\title{
Public Policy for a Free Economy
}

\author{
Remarks by DARRYL R. FRANCIS, President, Federal Reserve Bank of St. Louis, \\ Before the Students and Faculty of Washington University, for the \\ Dedication of the Center for the Study of American Business \\ Washington University, April 3,1975
}

T IS A distinct privilege to be the first speaker to address the Center for the Study of American Business. I view the inauguration of this center as a timely event, and one that marks the beginning of a program that could have a profound impact on the future of economic freedom in America. While my discussion will be limited to economic freedom, the ideas that I will express have a bearing on all freedoms - economic, social, and political. In my view the three are interdependent, and no one of them can exist without the others.

Let me begin by stating the basic premises upon which the discussion will rest. I view economic freedom as the freedom to determine and to seek to satisfy one's own wants as he sees them. Aside from its desirability as an end in itself, I subseribe to the widely held doctrine that the promotion of economic freedom is consistent with the attainment of the maximum possible standard of living for society. According to this view, state regulation should be viewed with suspicion as a potential enemy of society's material well-being. On the other hand, maximum freedom for individuals to act in their own self interest should be viewed as a source of the variety and diversification of ideas, experiments, and innovations which lead to the discovery of new products and more efficient means of production. If one accepts these premises, then a free economy should be viewed not only as precious in itself, but also as the most promising means by which the standards of living of all members of society can be raised.

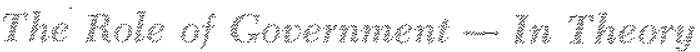

If we accept the foregoing proposition, as $I$ am sure most of us do, what then is the role of public policy in assuring a free economy? I see the role as follows. The maintenance of maximum economic freedom demands the organization of our economic life largely through individual participation in a game with definite rules. The necessity of rules arises because absolute economic freedom is impossible. One man's freedom can conflict with another's security and property rights. Hence, each person must give up some freedom in order to resolve individual conflicts. The major problem is determining those freedoms which the individual should give up in order to resolve conflict with others.

Just as a good game requires player acceptance of both the rules and an umpire to interpret and enforce such rules, so a free society requires that its members agree on the general rules that will govern relations among themselves, and on some device for enforcing compliance with them. Unfortunately, we cannot rely on custom or consensus alone to interpret and to enforce the rules; we need an umpire. These then are the basic roles of government in a free economy - to provide a means whereby we can establish some set of general rules, and to enforce compliance with the rules on the part of those few who would otherwise not play the game.

The advocate of a laissez-faire policy today realizes that there is a constructive role for government in the economy; he is not an anarchist. He recognizes that a system which promotes maximum economic freedom may not be a god-send and that its existence depends, in part, upon affirmative government action. However, he also recognizes that each new governmentally enacted rule of the game involves a loss of some freedom. Herein lies the problem; where do we draw the line? At what point does affirmative government action begin to have a net negative impact on economic freedom?

I can offer you no hard and fast principles on how far it is appropriate to use government to maximize economic freedom. However, I would suggest to you that in any particular case of proposed intervention, we should make up a balance sheet, listing separately the advantages and disadvantages of the proposed policy. Most importantly, we must always enter on the liability side of any proposed government intervention its effect in threatening freedom, and give this effect considerable weight. For it is an indisputable, yet 
frequently overlooked, reality that every new rule has its costs in terms of a loss of some freedom.

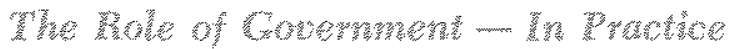

We have witnessed abroad the culmination of movements from constitutional government to dictatorships, from freedom back to authority. This spectacle, for most of us, is revolting, and something to be avoided at all costs. Yet, faced with the same problems as these other nations, we too have often adopted measures which call for more government authority and less individual freedom. We have often been too eager to justify and rationalize policies which propel us in a direction in which we overwhelmingly disapprove. As an indicator of how far and how fast we have moved in this direction, consider for a moment just a few facts and figures which are indicative of the tremendous growth of the government's influence on our economy.

1) It took 186 years for the Federal budget to reach the $\$ 100$ billion mark, a line we crossed in 1962 , but in only nine more years we reached the $\$ 200$ billion mark, and in only four more years we broke the $\$ 300$ billion barrier.

2) In 1930, prior to the New Deal, government spending at all levels accounted for just 12 percent of our gross national product. Today, government spending accounts for over 32 percent of our gross national product, and if present trends continue, government could account for as much as 60 percent of GNP by the year 2000 .

3) As the role of government has increased, the bureaucracy has also grown so that today one out of every six working men and women in this country works directly for either Federal, state, or local government.

Why is it, in light of the record, that the burden of proof still seems to rest on those of us who oppose new government programs which curtail our freedoms? Why is it that society seems so bent on curtailing the very freedoms that have netted us the highest standards of living and economic freedom in the entire world?

I submit to you that the reason for this drift is that there are natural biases in its favor. One of these biases has to do with what I will call the regulatory reflex that seems to have grown to almost epidemic proportions in our country. The other has to do with the same political realities which led Joseph Schumpeter to argue thirty years ago that there was an irreconcilable conflict between democracy and free enterprise.

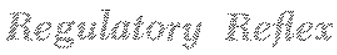

The regulatory reflex operates in the following manner. Upon observation of what some individuals deem an undesirable result produced by the free enterprise system, government officials or the press suggest that this is an area in which the government should "do something." This usually has meant the creation of a powerful new government agency, or an increase in the powers of an existing one. Such an agency is em powered to make decisions regarding the allocation of resources according to its own interpretations of what is best, rather than leaving the outcome to determination by the market process.

Implicit in this reflex is the assumption that the free market system produces undesirable results and that government planning is the means of achieving a more desirable end. Unfortunately, the desired end sought by a group of regulators is frequently not the same as that which the members of society would choose for themselves. The process often results in some group of zealots determining that others should not have what they want, but rather should accept that which the regulators consider "best" for them. This type of thinking, combined with the power to implement it, poses a tremendous threat to freedom, and yet it is becoming increasingly common. For example, wit. ness the proposed compulsory health insurance, social security, seat belt interlock mechanisms, and the issuance of food stamps instead of money to the poor, and the not so poor, to name just a few.

Another aspect of this regulatory reflex is that there are many people who still subscribe to the medieval notion that all business is a zero-sum game. That is, many people believe that one person's profit is another person's loss. Such notions are behind the frequently heard demands that the government should intervene in the market to limit what some consider to be the "obscene" profits of entreprenenrs and "protect" the powerless consumer. This kind of thinking is based on a notion that is absolutely false. Its acceptance requires that we also accept the proposition that some parties to all transactions are either irrational or victims of a fraud.

Free individuals will enter a eransaction only if they can benefit their own interests as a result. Business transactions are never a zero-sum game as long as the participants are free to choose for themselves and as long as they have alternative choices. There is 
no question that there are shoddy practices in every profession and that market economies produce goods that are often undesirable to some individuals or poorly made. However, the beauty of the free market system is that if the consumer does not want to purchase such products, he has alternatives, and the businesses that produce them will either shift to accommodate consumer desires or they will fail. The fact is that the alternative to free markets, planning by government bureaucracies, also results in the production of shoddy and expensive products (the postal service and antomobile modifications, for example). The crucial difference, however, is that the plans pursued by bureaucracies are not subject to the forces of market competition, and therefore there is no way to test their relative efficiency or acceptability.

I believe that much of the blind faith in the efficacy of goverment intervention stems from impatience and shortsightedness on the part of many individuals, aided, of course, by the lobbying of those who stand to gain directly from a particular regulatory proposal. Most policies are fomulated with an eye to the short run. In a familiar pattern we see a situation arise in which the short-run outcome of the interaction of free market forces is considered by many to be less than socially optimal. The key question is what is the alternative? For example, we have experienced several years of inflation. Impatience leads many to clamor for the quickest solution to the problem. Certainly, in this case, many people believe that wage and price controls fit the bill. A rigid system of wage and price controls will in fact keep reported prices from rising in the short run. Unfortunately, such controls will also create shortages and distortions in the economy that result in severe bottlenecks in the production process. Reported prices are temporarily fixed, but the consumer is robbed of the right to purchase those items which are in short supply. However, everyone concentrates on the immediate impact of the controls on the movement of reported price indices and says, "You see how simple that was?"

So it is with most cases of state intervention. The seemingly beneficial effects are direct, immediate, and visible. On the other hand, the undesirable effects are often gradual and indirect, and are frequently considered only when they actually occur, if even then. However, the ignored long-run costs of such intervention eventually show up. And, when they do, there is a call for more short-run intervention to correct the problems which arose as a result of the earlier policies. Over a long period of time there is a cumulative and disastrous effect which erodes freedom and detracts from the efficiency of the economy.

Unfortunately, it is a truism that regulation begets further regulation and that regulations outlive their rationale. Though most government regulation was enacted under the guise of protecting people from abuse, much of today's regulatory machinery only provides jobs for the regulators, increases the cost of doing business, and shelters those who are being regulated from the normal consequences of free enterprise competition. In some cases, the Interstate Commerce Commission for example, the original threat of abuse no longer exists. In other cases, the regulatory machinery has simply become perverted. In still other cases, the machinery was a mistake from the start. In any case, the individual, from whatever presumed abuse he is being spared, is paying for the regulation through both a loss of freedom and a loss of material wellbeing.

While many regulatory programs seem to accom" plish their goal (desirable or not) in the short run, they are seldom successful in the long run. The central problem with all of these measures is that they all involve an abridgement of some freedoms. They seek through government to force some individuals to act against their own immediate interests in order to promote a supposedly general interest. They substitute the values of outsiders for the values of participants. Some people are telling others what is "good" for them, or else the government is taking from some to benefit others. These measures are therefore counter to the attempt by millions of individuals to promote their own interests and to live their lives by their own values. This is the major reason why the measures have so often had the opposite of the intended effects.

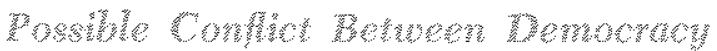

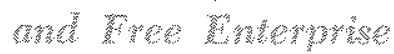

Despite the fact that the regulatory reflex contaminates so much of our society, I do not believe that it could be as pervasive as it has been were it not provided with a political framework conducive to its proliferation. Consider the situation in a community in which the mass of the people are in favor of economic freedom of choce in their daily lives and are against government direction. As will normally happen, however, many groups are formed which perceive an opportunity for material gain through a particular form of government intervention. Under the guise of such slogans as "fair prices;" "equitable wages," or "fair trade" laws, they perceive an opportunity to be pro- 
tected from the sources of competition. In snch situatons a political party hoping to achieve and maintain power will have little choice but to use its power to buy the support of these special interest groups by catering to their legislative demands. The reason they will do so is not necessarily because they think that the majority of society is interventionist, but rather because they cannot achieve and retain a majority if they do not solicit support through the promise of special advantages. This means, in practice, that even a statesman wholly devoted to the maintenance of freedom, and who realizes that every new regulation is an abridgement of those freedoms, will be under constant pressure to satisfy the interventionist demands of organized groups.

Some special interest groups undoubtedly favor intervention not for personal gain as much as for what they determine to be for the "good of society." These groups labor under the illusion that they can draft a law to prevent every outcome which they, and frequently only they, deem undesirable. In this case, the operation of the regulatory reflex merely feeds an insatiable appetite for power on the part of those who wish to impose their values on the rest of society. When regulation fails to accomplish its goals, as it almost inevitably does, these people do not call for the repeal of the laws. Instead, they push to amend them into infinite complexity until the purpose of the original law is lost. As a result, the hand of regulation ends up touching every aspect of human action. It is not only wasteful, but serves to destroy incentive and to discourage ingenuity.

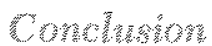

It is ironic that groups which constantly look for problems in our country insist on inhibiting the ability of the economy to respond to these problems. For example, present technology does not permit us to have surgically clean air and plentiful electricity at less cost at the same time. However, there is no reason to believe that future technology conld not provide those benefits. The essential ingredient is freedom to react to incentives and an understanding that individual liberty is not only precious, but efficient. Just as thought control is the great enemy of the freedom of inquiry in academia, economic controls are the great enemy of economic freedom and the entrepreneurial spirit which is needed to solve our problems.

Rediscovering the indivisibility and efficiency of political and economic freedom will take time in a society which has become so accustomed to overreliance on government intervention. The political and intellectual bias against the free market is strongly entrenched, and there are some who will always find a platform to continue to feed this bias out of a complete misunderstanding of both the political and the market functions.

Those of us who firmly believe in the preciousness and efficiency of a system which maximizes economic freedom more often than not find ourselves on the defensive. Given the biases that seem to continuously propel our society away from such a system, being merely defensive is not nearly enough. We must take the offensive and encourage others to restudy the philosophy of free enterprise. It is in this regard that I applaud the inauguration of the Institute for the Study of American Business. We need to drive home the point that every new rule of the game involves the loss of some freedom and that one camnot erode freedom in one sector of society without adversely affecting all others. In other words, we must insist that public policy be based on a recognition of the desirability, efficiency, and interdependence of political, social, and economic freedom.

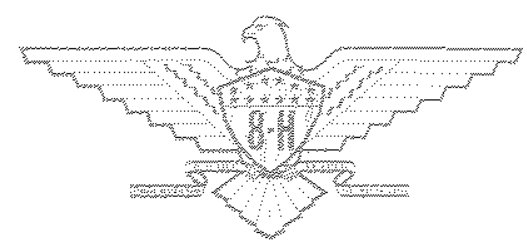

